\title{
Immunoglobulin gene rearrangement in immunoproliferative small intestinal disease (IPSID)
}

\author{
WENDY J SMITH, S K PRICE,* P G ISAACSON \\ From the Department of Histopathology, School of Medicine, University College London and the *Department \\ of Pathology, Medical School, University of Cape Town, Observatory, South Africa
}

SUMMARY Analysis of DNA from the mucosal tissue of three patients with immunoproliferative small intestinal disease (IPSID) and $\alpha$ chain disease, two of whom had early stage disease responsive to antibiotics, showed monoclonal heavy and light chain gene rearrangements in all cases. These findings suggest that IPSID is neoplastic even in its early stages, but that the neoplastic cells respond to normal stimuli. Monoclonal lymphoid populations could not be detected in circulating lymphocytes from these patients, which raises the possibility that the circulatory pathways of lymphocytes derived from human gut associated lymphoid tissue may not necessarily parallel those in experimental animals.

Immunoproliferative small intestinal disease (IPSID) occurs predominantly, but not exclusively, in the Middle East, and is characterised by diarrhoea, weight loss, abdominal pain and finger clubbing. ${ }^{2}$ The pathological basis of these features is a heavy plasmacytic or lymphoplasmacytic infiltrate of the upper small intestinal mucosa and related mesenteric lymph nodes. In most, if not all, cases these plasma cells synthesise, without necessarily secreting, ${ }^{3}$ an abnormal $\alpha_{1}$ immunoglobulin heavy chain ( $\alpha$ chain disease). Malignant intestinal lymphoma (Mediterranean lymphoma) often arises in the setting of IPSID and opinions are divided as to whether IPSID is a malignant proliferation de novo or whether the onset of Mediterranean lymphoma represents a complication of a benign disorder. ${ }^{124}$ The latter view is supported by the evident response of some cases of uncomplicated IPSID to broad spectrum antibiotics ${ }^{1245}$ while cases of Mediterranean lymphoma require more radical treatment. Decisions regarding treatment are based on the interpretation of the histology of intestinal biopsy specimens. ${ }^{4}$ The histopathological differential diagnosis between uncomplicated IPSID and Mediterranean lymphoma can, however, be extremely difficult and is subject to sampling error.

Central to the argument on the nature of the lymphoproliferation in IPSID, and hence the optimum

Accepted for publication 2 June 1987 choice of treatment, is the clonality of the mucosal plasma cell infiltrate in the early stages of the disease. The absence of light chains and the loss of the variable region of the abnormal $\alpha_{1}$ heavy chain precludes the use of the two most common criteria of monoclonality: light chain restriction and monoclonal idiotype expression. Although cases showing light chain restriction have been described, ${ }^{6}$ these were in established cases of Mediterranean lymphoma rather than in examples of early IPSID. Accordingly, we analysed the DNA from three cases of IPSID for evidence of monoclonal rearrangements of both heavy and light chain immunoglobulin genes. Two cases were examples of early IPSID that had responded to conservative treatment and one was of established Mediterranean lymphoma. All three patients were from the Cape region of South Africa, where IPSID is a well recognised disease.

\section{Patients and methods}

\section{CASE 1}

A 26 year old woman complained of diarrhoea and abdominal pain associated with a weight loss of $6 \mathrm{~kg}$. Apart from emaciation, there were no abnormal physical findings. Gastroduodenoscopy showed slight nodularity of the first part of the duodenum. The only clinically important biochemical finding was the presence of serum $\alpha$ chains. The duodenal biopsy specimen was consistent with a diagnosis of IPSID and the 
patient underwent a staging laparotomy with full thickness jejunal and mesenteric lymph node biopsy, at which time fresh tissue was collected. Treatment consisted initially of metronizadol to eradicate Giardia followed by long term tetracycline $1 \mathrm{~g}$ twice a day. Six months after diagnosis the patient remained well, having regained her original weight. Serum $\alpha$ chains were undetectable. Fourteen months after diagnosis, when peripheral blood was taken, she remained well and was 30 weeks pregnant at the time of writing.

\section{CASE 2}

A 20 year old man gave a four year history of diarrhoea and a weight loss of $18 \mathrm{~kg}$. Examination showed that he was physically wasted with no other clinically important findings. Gastroduodenoscopy yielded normal results as did biochemical investigations, except for the presence of serum $\alpha$ chain. Laparotomy with full thickness jejunal and mesenteric lymph node biopsy was carried out and fresh tissue retained. Peripheral blood was collected simultaneously. The patient started on tetracycline $1 \mathrm{~g}$ twice a day and parenteral nutrition-with pronounced clinical improvement. A follow up jejunal biopsy at four months was unchanged.

\section{CASE 3}

A 15 year old boy gave a three month history of abdominal pain, weight loss, and diarrhoea. Examination showed general wasting and clubbing of his nails. Gastroduodenoscopy showed nodular infiltration of the duodenum; serum $\alpha$ chain was present. Laparotomy showed thickening of the entire small intestine with enlarged mesenteric lymph nodes, and full thickness jejunal and mesenteric lymph node biopsy specimens were taken and submitted fresh. Prednisone $40 \mathrm{mg}$ daily, tetracycline $500 \mathrm{mg}$ twice daily, and parenteral nutrition were started. At follow up 15 months after admission the patient remained symptomatic and $\alpha$ chain was still detectable in his serum. Peripheral blood was collected at this time. Follow up biopsies were refused by the patient who then received total abdominal irradiation with good clinical response.

Standard formalin fixed, paraffin embedded sections from the full thickness jejunal and mesenteric lymph node biopsy specimens were prepared and stained with haematoxylin and eosin. Immunohistochemistry was performed on these and on cryostat sections prepared from fresh tissue, snap frozen in liquid nitrogen. Sections were stained with antibodies to all immunoglobulin heavy and light chain and selected $B$ cell and $T$ cell antigens.

Frozen sections were prepared from tissue snap frozen in liquid nitrogen to check that the tissue being submitted for DNA analysis was representative. After collection in edetic acid, lymphocytes from peripheral blood from all three patients were separated on a Ficoll hypaque gradient, harvested, and snap frozen in liquid nitrogen. High molecular weight DNA was extracted by standard methods from the biopsy specimens and peripheral blood lymphocytes. ${ }^{8}$ After digestion with HindIII, EcoR1, BamH1, and BglII restriction enzymes the fragments were separated according to size on an agarose gel by electrophoresis and Southern blots ${ }^{9}$ prepared using Gene Screen Plus filters (DuPont). Table 1 details the recombinant DNA probes used and their sources. They were radiolabelled with ${ }^{32} \mathrm{P}-\mathrm{dCTP}$ by the random hexanucleotide method ${ }^{10}$ and hybridised to the filters under conditions recommended by the manufacturer. After stringent washing the filters were exposed to pre-fogged $x$-ray film.

\section{Results}

The histological appearances (table 2) of the biopsy specimens in cases 1 and 2 showed a dense plasma cell infiltrate confined by the muscularis mucosae. This was focal in case 1 , whose biopsy specimen also showed lymphoepithelial lesions, ${ }^{11}$ and diffuse in case 2 . The lymph node of case 1 showed reactive hyperplasia while that of case 2 showed infiltration with mature plasma cells. The small intestinal biopsy specimen of case 3 showed a nodular mucosal lymphoplasmacytic infiltrate which breached the muscularis mucosae. Lymphoepithelial lesions were present; lymph node architecture was effaced by a similar infiltrate.

Immunohistochemistry of paraffin sections showed cytoplasmic Ig of the $\alpha_{1}$ subclass in the plasma cells of all patients. No light chain was shown in cases 1 and 3 , but $\kappa$ light chain restriction was present in case 2 . Using frozen sections the mucosal lymphocytes in case 1 were SIg negative while in case 3 SIgA $_{1}$ without light chain was demonstrable. Mucosal lymphocytes were virtually absent in case 2 .

DNA analysis (table 3, figure) using the Jh probe ${ }^{12}$ showed the presence of a clone of $B$ cells in all three biopsy specimens. Rearrangements were detected with four different restriction enzymes. In samples from cases 1 and 3 only one rearranged band was detected. Both alleles, however, exhibited a nongermline configuration in case 2 . Only germline frag-

Table 1 Recombinant DNA probes used

\begin{tabular}{lll}
\hline Probe & Code name & Reference \\
\hline Heavy chain joining region (Jh) & C76R51A & 12 \\
$\kappa$ light chain constant region (Cא) & pUCR17 & 13 \\
$\lambda$ light chain constant region (C $\lambda$ ) & pUC $\lambda 5$ & 14 \\
\hline
\end{tabular}


Table 2 Histological appearances of biopsy specimens

\begin{tabular}{llll}
\hline Histology/immunocytochemistry & Case 1 & Case 2 & Case 3 \\
\hline Lymphoplasmacytic infiltrate & Mucosal & Mucosal & Mucosal and submucosal \\
Lymphoepithelial lesions & Present & Absent & Present \\
Lymph nodes & Hyperplasia & Plasma cells & Infiltrated \\
Cytoplasmic $\alpha_{1}$ heavy chain & Plasma cells & Plasma cells & Plasma cells \\
Surface $\alpha_{1}$ heavy chain & Absent & Absent & Present (lymphocytes) \\
Light chain & Absent & Present (kappa) & Absent \\
\hline
\end{tabular}

ments hybridising to Jh were observed in DNA extracted from the three blood samples.

The probing of BglII and BamH1 digests of DNA from cases 1 and 3 with the $C \kappa$ probe yielded germline fragments. ${ }^{13}$ Analysis of the C $\lambda$ locus in the DNA extracted from all three biopsy specimens indicated the presence of hybridising fragments which did not resemble any published germline patterns. ${ }^{14-17}$ Probing DNA extracted from peripheral blood lymphocytes from the patients with $C \lambda$, however, showed a pattern of hybridising fragments which differed from that seen in the DNA of the biopsy specimens. We detected a similar pattern in several control samples (unpublished results) and it resembles a published germline $C \lambda$ configuration. Rearrangement of both the $\mathrm{C} \kappa$ alleles was detected in the DNA from the biopsy specimens from case 2 , but not from the peripheral blood lymphocytes.

\section{Discussion}

The presence of a clone of $B$ cells in each biopsy specimen was shown by the non-germline fragments which hybridise to the Jh probe in DNA purified from these samples. The use of four different restriction enzymes excludes the possibility that polymorphisms at this locus are responsible for these additional bands. Rearrangement of the immunoglobulin heavy chain (IgH) locus occurred at one allele in cases 1 and 3, while this occurred at both alleles in case 2 . In this case three of the four restriction enzymes showed two non-germline fragments while three EcoR 1 fragments hybridised to the probe in addition to the germline fragment. It would seem likely from the data concerning the three restriction enzymes that rearrangement had occurred in two alleles but that one of the rearrangements had introduced an additional EcoR1 site into the region hybridising to the Jh locus. This may have occurred by the deletion of DNA $3^{\prime}$ to the $\mathrm{C} \alpha$ locus during somatic recombination (Rabbitts TH, personal communication). Cloning and sequencing the rearranged fragments would elucidate the somatic recombination mechanisms. Similar sized EcoR1 fragments have been observed in genetic analysis of acute undifferentiated leukaemia cells. ${ }^{18}$
Probing of the BamHI and BglII digests showed that only germline bands hybridising to $\mathrm{C} \kappa$ were present in DNA from cases 1 and 3. Both $\mathrm{C} \kappa$ alleles had undergone rearrangement in the biopsy specimens from case 2 . Analysis of DNA from non-T/nonB leukaemias led Korsmeyer et $a^{19}$ to postulate a developmental hierarchy in which $\mathrm{IgH}$ gene rearrangement precedes that of $\kappa$, which in turn precedes that of $\lambda$. As our data do not suggest that $\mathrm{C} \kappa$ rearrangement occurred in cases 1 and 3 despite the $C \lambda$ rearrangement, three possible hypotheses can be put forward. The $\mathrm{C} \kappa$ genes in the clone may have been deleted, but this was masked by the presence of nonclonal cells which still retained the $\mathrm{C} \kappa$ germline configuration. Alternatively, the $\mathrm{C} \kappa$ genes in the clone may have undergone rearrangement in such a manner to recreate the germline fragments, but this is unlikely as both enzymes indicate rearrangement. The third possibility is that this hierarchy does not apply in IPSID.

Interpretation of the data obtained with the $C \lambda$ probe was complicated by the nature of the locus: it is highly polymorphic and composed of between six and nine genes per haploid genome. ${ }^{16}$ Comparison of the patterns obtained from the DNA purified from the biopsy specimens with that extracted from the peripheral blood lymphocytes suggested that rearrangement of this complex locus had occurred in biopsy specimens from all three patients. If no rearrangement had occurred it could be predicted that the patterns obtained from the tissue would be identical with that in peripheral blood leucocytes which showed no evidence of clonal rearrangements.

The demonstration of rearrangement in the $\lambda$ light chain loci in cases 1 and 3, despite the lack of immunohistochemical evidence for synthesis of $\lambda$ light chain, can be interpreted in several ways. The first possibility is that $\lambda$ chains were present at the cell surface but only at levels not detectable by immunohistochemistry. The second is that both light and heavy Ig genes were correctly transcribed and translated, but that the assembly of the complete molecule or its transport to the membrane was impaired. Alternatively, the $C \lambda$ rearrangement may have generated a gene with incorrect control signals such as initiation, splicing, or termination, which could not be correctly 
Table 3 DNA analysis using Jh probe

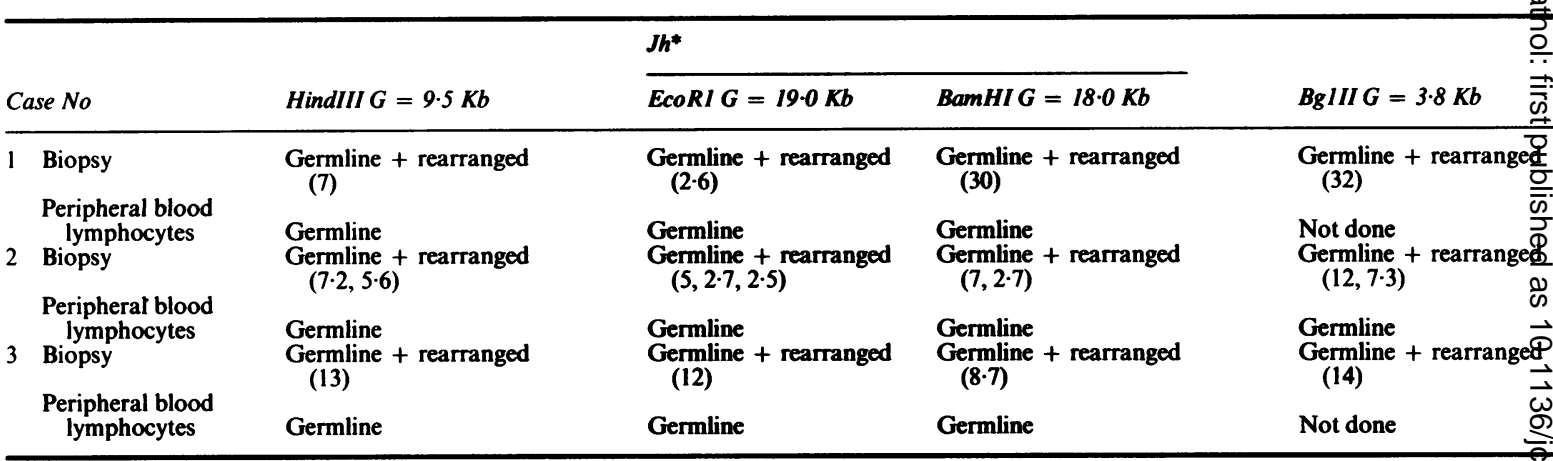

* Represent sizes of rearranged bands in kilobases. For $\mathbf{C} \lambda$ band sizes of all hybridising fragments are detailed. Fragment sizes which are outside the range of the molecular weight markers used are indicated by $30+$.

transcribed or translated. The analysis of light chain genes in case 2, whose tumour showed $\kappa$ light chain restriction, showed the unusual, but not unprecedented, evidence of both $\kappa$ and $\lambda$ rearrangements. ${ }^{20} 21$

Histopathologists recognise three stages of IPSID. ${ }^{4}$ In the first stage (A) a benign appearing plasma cell or lympohoplasmacytic infiltrate is confined to the mucosa and mesenteric lymph nodes. In stage B cytologically neoplastic cells begin to appear in this infiltrate which extends into the submucosa and beyond, while in stage $C$ there is frank recognisable lymphoma. Patients in stage $A$ may respond to antibiotics alone (as is well shown by case 1 in this report, and, to a lesser extent, by case 2). The pathology in case 3 is that of stage $B$ and his failure to respond to conservative treatment was expected. In view of the response of some patients to antibiotics alone it has been suggested that stage $A$ is a benign non-lymphomatous disorder. ${ }^{12}$ The implication is that the plasma cell proliferation is polyclonal at this stage, with a single clone emerging as the disease progresses. Until the advent of DNA analysis of immunoglobulin gene rearrangements, monoclonal lymphoproliferation could only be shown by showing light chain restriction or, using anti-idiotype serum, a single idiotype in the synthesised immunoglobulin. Characteristically, light chains are only rarely synthesised in IPSID; nevertheless, the finding of light chain restriction in the plasma cells of some cases ${ }^{6} 7$ and in case 2 in this report, strongly supports a monoclonal proliferation. The use of anti-idiotype sera is vitiated in IPSID as the immunoglobulin domain responsible for the synthesis of idiotype - namely, the variable region-is characteristically absent from the
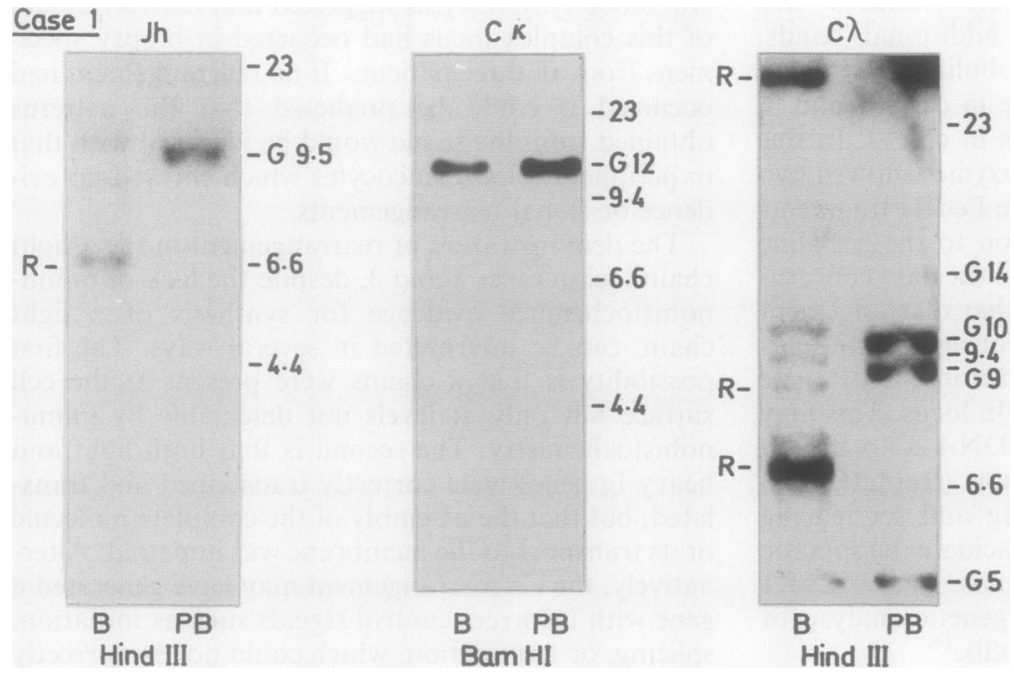

Examples of filter hybridisations of DNA extracted from cases 1,2 , and 3 probed with $J h, C \kappa$, and $C \lambda$. Rearranged fragments are indicated by $\boldsymbol{R}$, germline by $\boldsymbol{G}$. Molecular weight markers and DNA fragment sizes are all in kilobases. Lanes labelled $B$ illustrate DNA extracted from biopsy specimens. Those labelled $P B$ are from peripheral blood lymphocytes. Restriction enzymes used are given beneath each example.

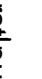




\begin{tabular}{|c|c|c|c|}
\hline \multicolumn{2}{|l|}{$C \kappa^{*}$} & \multicolumn{2}{|l|}{$C \lambda$} \\
\hline BamHl G $=12.0 \mathrm{~Kb}$ & $B g l I I G=13.0 \mathrm{~Kb}$ & EcoRI & HindIII \\
\hline Germline & Germline & $\begin{array}{l}\text { Germline }+ \text { rearranged } \\
(15,8 \cdot 6,7)\end{array}$ & $\begin{array}{c}\text { Germline + rearranged } \\
(30+, 10,9,8,7,5)\end{array}$ \\
\hline Germline & Not done & $\begin{array}{l}\text { Germline } \\
(15,8 \cdot 6)\end{array}$ & $\begin{array}{l}\text { Germline } \\
(14,10,9,5)\end{array}$ \\
\hline $\begin{array}{l}\text { Germline + rearranged } \\
(10 \cdot 1,7)\end{array}$ & $\underset{(9,5.8)}{\text { Germline }}+$ rearranged & Not done & $\begin{array}{l}\text { Germline }+ \text { rearranged } \\
(21,10,9,7,5)\end{array}$ \\
\hline Germline & Germline & Not done & $\begin{array}{l}\text { Germline } \\
(21,10,9,5)\end{array}$ \\
\hline Germline & Germline & $\begin{array}{c}\text { Germline }+ \text { rearranged } \\
(21,18 \cdot 5,8 \cdot 6,7 \cdot 3)\end{array}$ & $\begin{array}{c}\text { Germline + rearranged } \\
(16,13,10,9,5,3)\end{array}$ \\
\hline Germline & Not done & $\begin{array}{l}\text { Germline } \\
\quad(21,8 \cdot 6)\end{array}$ & $\begin{array}{l}\text { Germline } \\
\quad(14,10,9,5)\end{array}$ \\
\hline
\end{tabular}

$\alpha_{1}$ heavy chain in this disease. The demonstration of clonal rearrangements of immunoglobulin genes in our three patients, two of whom were in stage $A$, is, we believe, clear evidence that the lymphoproliferation in IPSID is monoclonal from the start.

Given that clonality is the cardinal feature of neoplasia, one must conclude that IPSID is lymphomatous in all its stages. Our findings are comparable with those of Weiss et $a l,{ }^{22}$ who recently carried out DNA analysis on cases of lymphomatoid papulosis of the skin, an apparently benign disorder which progresses to $\mathrm{T}$ cell lymphoma in $20 \%$ of cases. Using DNA analysis Weiss $e t$ al found evidence of $T$ cell monoclonality in the benign stage of the disease and suggested that at this stage the clonal population and host response are in balance. This could well be the case in stage A of IPSID where the neoplastic clone seems to be responding normally to a stimulus of lumenal bacterial overgrowth and involuting when this stimulus is removed by broad spectrum antibiotics. Claims of "cure" using antibiotics alone should be treated with caution as IPSID can have a long natural history before lymphomatous masses become evident, and relapses after an initial response to antibiotics are common. ${ }^{4}$ In view of our findings should all cases of IPSID receive chemotherapy or radiotherapy regardless of stage? Unless one can be certain that this form of treatment will destroy the malignant clone, it is probably wise to withhold it until such time as antibiotics fail to control the disease. Newer forms of treatment for lymphoid malignancy, possibly immunologically based, however, must surely emerge and the knowledge that IPSID is a neoplasm de novo is important to keep in mind in

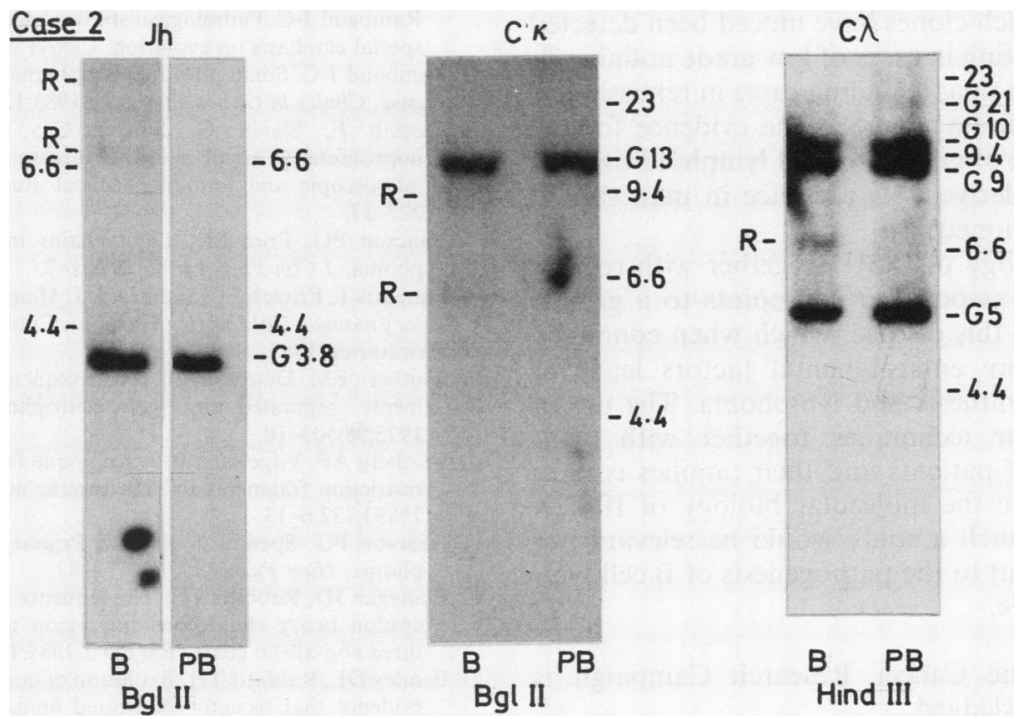



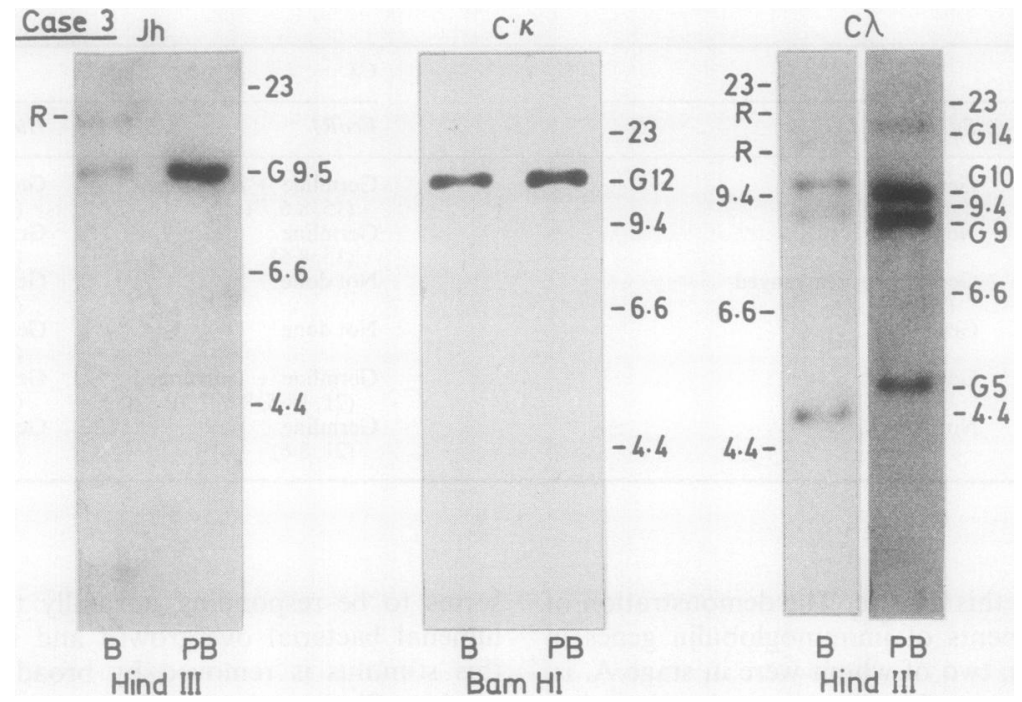

this respect. Furthermore, when follow up is likely to be difficult it may be prudent to treat patients with a lymphoma regimen regardless of the pathological stage.

Studies on animals have shown that mucosal plasma cells are derived from Peyers patch lymphocytes indirectly via the mucosal lymphatics and the circulation. ${ }^{23}$ We therefore might have expected to detect a monoclonal population of cells in the circulation in our cases, especially in cases 2 and 3 with active disease. Such clones have indeed been detected by Southern blotting in cases of low grade nodal nonHodgkin's lymphoma, including cases in remission. ${ }^{24}$ In view of our findings and as the evidence for the circulatory phase of gut associated lymphoid tissue is entirely animal derived, its presence in man should perhaps be questioned.

The epidemiology of IPSID together with reports of specific HLA association 2526 points to a genetic predisposition in this disease, which when combined with one or more environmental factors leads to abnormal IgA synthesis and lymphoma. The use of further molecular techniques together with cytogenetic studies of patients and their families is indicated to elucidate the molecular biology of IPSID. The findings of such a study would be relevant not only to IPSID, but to the pathogenesis of B cell lymphoma as a whole.

Support from the Cancer Research Campaign is gratefully acknowledged.

\section{References}

1 Report of a WHO meeting of investigators. Alpha-chain disease and related small-intestinal lymphoma. Archives Francaises des Maladies de l'Appareil Digestif 1976;65:591-607.

2 Khojasteh A, Haghshenass M, Haghighi P. Immunoproliferativesmall intestinal disease. A "third-world lesion". $N$ Engl J Med 1983;308:1401-5.

3 Rambaud JC, Modigliani R, Nguyen Phuoc BK, Lejeune R. Non-secretory alpha-chain disease in intestinal lymphoma. $N$ Engl J Med 1980;303:53.

4 Galian A, Lecestre M-J, Scotto J, Bognel C; Matuchansky C Rambaud J-C. Pathological study of alpha-chain disease, with special emphasis on evolution. Cancer 1977;39:2081-101.

5 Rambaud J-C. Small intestinal lymphomas and alpha-chain disease. Clinics in Gastroenterology 1983;12:743-66.

6 Asselah F, Slavin G, Sowter Gay, Asselah H. Immunoproliferative small intestinal disease in Algerians. 1. Light microscopic and immunochemical studies. Cancer 1983;52. 227-37.

7 Isaacson PG, Price SK. Light chains in Mediterranean lymphoma. J Clin Pathol 1985;38:601-7.

8 Maniatis T, Fritach EF, Sambrook J. Molecular cloning, a laboratory manual. Cold Spring Harbour: Cold Spring Harbour Laboratories, 1982.

9 Southern EM. Detection of specific sequences among DNA fragments separated by gel eletrophoresis. J Mol Biol 1975;98:503-10.

10 Feinberg AP, Vogelstein B. A technique for radiolabelling DNA restriction fragments to high specific activity. Annal Biochem 19833;132:6-13.

11 Isaacson PG, Spencer J, Finn T. Primary B-cell Gastric Lymphoma. Hum Pathol 1986;17:72-82.

12 Flanagan JD, Rabbitts TH. The sequence of an immunoglobulin epsilon heavy chain constant region gene and evidence for three non-allelic genes. EMBO J 1982;1:655-60.

13 Bentley DL, Rabbitts TH. Evolution of immunoglobulin $V$ genes: evidence that recently duplicated human Vk sequences have 
diverged by gene conversion. Cell 1983;32:181-9.

14 Rabbitts TH, Forster A, Matthews JG. The breakpoint of the Philadelphia chromosome 22 in chronic myeloid leukaemia is distal to the immunoglobulin $\lambda$ light chain constant region genes. Mol Biol Med 1983;1:11-9.

15 Hollis GF, Heiter PA, McBride OW, Swan D, Leder P. Processed genes: a dispersed immunoglobulin gene bearing evidence of RNA-type processing. Nature 1982;290:321-5.

16 Taub RA, Hollis GF, Hieter PA, Korsymeyer S, Waldmann TA, Leder $P$. Variable amplification of immunoglobulin $\lambda$ light chain genes in human populations. Nature 1983;304:172-4.

17 Foroni L, Catovsky D, Rabbitts TH, Luzzatto L. DNA rearrangements of immunoglobulin genes correlate with phenotypic markers in CB cell malignancies. Mol Biol 1984;2:63-79.

18 Raghavachar A, Bartram CR, Ganser A, Heil G, Kleihauer E, Kubanek B. Acute undifferentiated leukemia: Implications for cellular origin and clonality suggested by analysis of surface markers and immunoglobulin gene rearrangement. Blood 1986;3:658-62.

19 Korsmeyer SJ, Hieter PA, Ravetch JV, Poplack DHG, Waldmann TA, Leder P. Developmental hierarchy of immunoglobulin gene rearrangements in human leukaemic pre-Bcells. Proc Natl Acad Sci USA 1981;78:7096-100.

20 Hardy RR, Dough JL, Hayakawa K, Jager G, Herzenberg LA, Herzenberg LA. Frequent lambda light chain rearrangement and expression in a Ly-1 B lymphoma with a productive kappa chain allele. Proc Natl Acad Sci USA 1986;83:1438-42.

21 Brito-Babapulle V, Melo JV, Foroni L, et al. Neoplastic kappa and lambda cells in a B-PLL with chromosome translocations of both light chain regions. Int J Cancer 1984;34:769-73.

22 Weiss LM, Wood GS, Trela M, Warnke RA, Sklar J. Clonal T cell populations in lymphomatoid papulosis. Evidence of lymphoproliferative origin for a clinically benign disease. $N$ Engl $J$ Med 1986;315:475-9.

23 Parrot DVM. The gut as a lymphoid organ. Clinics in Gastroenterology 1976;5:211-28.

$24 \mathrm{Hu}$ E, Trela M, Thompson J, et al. Detection of B cell lymphoma in peripheral blood by DNA hybridisation. Lancet 1985;ii: 1092-5.

25 Novis BH. Primary intestinal lymphoma in South Africa. Isr $J$ Med Sci 1979;15:386-9.

26 Nikbin B, Banisadre M, Ala F, Mojtabai A. HLA AW 19 B12 in immunoproliferative small intestinal disease. Gut 1979;20: 226-8.

Requests for reprints to: Professor PG Isaacson, Department of Histopathology, School of Medicine, University College London, University Street, London WCIE 6JJ, England. 